Article

\title{
Qualitative Assessment of the Economic Impacts of Horticulture Research and Extension at MSU Coastal Research and Extension Center
}

\author{
Benedict Posadas ${ }^{1, *(\mathbb{D}}$, Patricia Knight ${ }^{1}$, Eric Stafne ${ }^{1}$, Christine Coker $^{1}$, Eugene Blythe ${ }^{2} \mathbb{C}$, \\ Gary Bachman ${ }^{1}$, James DelPrince ${ }^{1}$ and Scott Langlois ${ }^{1}$ \\ 1 Coastal Research and Extension Center, Mississippi State University, Biloxi, MS 39532, USA; \\ patricia.knight@msstate.edu (P.K.); eric.stafne@msstate.edu (E.S.); cec117@msstate.edu (C.C.); \\ gary.bachman@msstate.edu (G.B.); jdelprince@pss.msstate.edu (J.D.); scott.langlois@msstate.edu (S.L.) \\ 2 College of Agriculture, Auburn University, Auburn, AL 36849, USA; blythek@auburn.edu \\ * Correspondence: ben.posadas@msstate.edu
}

Received: 18 November 2020; Accepted: 14 December 2020; Published: 16 December 2020

\begin{abstract}
This paper summarizes opinions on the economic impacts of horticulture research and extension at the Mississippi State University, Coastal Research and Extension Center. More than 8400 horticulture producers, master gardeners, research and extension staff, and nonprofit organizations participated in horticulture events during the last five years. Qualitative assessments of horticulture research and extension performed by the faculty and staff were solicited during voluntary surveys.
\end{abstract}

Keywords: economic impact; ornamental horticulture; fruits and nuts; vegetables; flowers

\section{Introduction}

Horticulture research and extension are essentially public goods funded for the benefit of the public. Economic impact assessments are necessary to justify the continued funding of these research and extension programs. As agricultural research budgets are being subjected to strict scrutiny, research centers or programs need to show that they are worth the investment of state, federal, or industry funds [1].

Horticulture researchers and extension specialists rely on industry feedback to document that research-based information is timely and relevant to both emerging and existing issues. Agricultural extension services are among the most common forms of public-sector support of knowledge diffusion [2]. Extension programs provide technical education services to farmers through demonstrations, lectures, contact with farmers, and other media [3]. Extension specialists provide farmers with technical information to better evaluate new technology prior to adoption and communicate feedback to technology suppliers. Extension plays an important role in disseminating new technology and bridging the gap between innovation in the laboratories and practice on the farm [4].

The sequence of the extension's impact starts with extension, and other information is communicated [2]. The shaping of knowledge and observations from other producers most likely leads to producers' adoption of new methods. As specialists convey the information to industry professionals, program evaluations document that the specialist expressed relevant data and did it in a readily usable format.

The overall goal of this paper is to present a qualitative assessment of the economic impacts of the horticultural research and extension program at the Mississippi State University (MSU) - Coastal Research and Extension Center (CREC). The specific objectives of this paper are as follows: 
- Present the participants' opinions on the economic impacts of research and extension programs on ornamental horticulture, vegetables, fruits, and nuts.

- Present the participants' preferred sources of information on research and extension programs on ornamental horticulture, vegetables, fruits, and nuts.

It is expected that the application of this new horticultural information will enable households, nonprofit organizations, or businesses to increase sales or funding, reduce costs, or increase savings. Before adopting or rejecting these new methods, they evaluate the adaptability to their respective households or businesses. The adoption or rejection decisions made by other households or enterprises also influence their choices. Expected benefits and costs will ultimately determine the final decisions of horticulture businesses, households, and nonprofit organizations in adopting or rejecting new horticulture methods. The quantitative assessment of the horticulture research and extension program's economic impacts at MSU-CREC is covered in a follow-up paper.

\section{Materials and Methods}

The environmental horticulture or green industry complex includes input suppliers, production firms, wholesale distribution firms, horticultural service firms, and retail operations [5]. In Mississippi, the green industry complex contributed $\$ 835$ million to the state gross domestic product and created a total of more than 15,000 jobs in 2013 [6].

Recent statistics showed the following acres to be devoted to horticulture, vegetable, fruit, and nut in Mississippi [7]:

6018 open acres of horticulture operations

5273 open acres of irrigated horticulture operations

4.289 million square feet of irrigated greenhouses

5350 acres of sod operations

5602 acres of open irrigated vegetable farms

1924 acres are grown with blueberries

1584 acres bearing with blueberries

6188 acres are grown with tree nuts

4382 acres have nut-bearing trees

\subsection{Sources of Primary Data}

The survey of opinions on the economic impacts covers the research and extension activities conducted by the faculty and staff of the MSU-CREC at its experiment stations and extension offices located in Coastal Mississippi. In these research and extension events, attendees were asked to participate in voluntary surveys conducted after some of these events.

The attendees of the Muscadine Field Days and Workshops (M-FD-WS) averaged more than 150 producers per year (Figure 1). The muscadine field day is held each year near the end of August at the McNeill Research Unit in McNeill, MS. Attendees hear short presentations about muscadine vineyard management. They are then allowed to taste the fruit from several cultivars in the field. The program draws attendees from many different nearby states, including Louisiana, Alabama, and Florida. Presentations are given by MSU Extension personnel and USDA-ARS scientists, and it is considered a joint effort between these two entities.

About 70 attendees per year participated in the Blueberry Workshops and Field Days (BB-FD-WS, Figure 1). The annual Mississippi Blueberry Education Workshop is held in Hattiesburg, MS at various locations, but primarily at the MSU Forrest County Extension office. The program has been either a whole or a half-day program, depending on funding availability. Speakers from MSU, USDA-ARS, and other outside institutions have contributed. Attendees learn about the latest in pest management, cultural techniques, and hot topics. The blueberry field day has been held at the USDA-ARS Thad 
Cochran Southern Horticultural Laboratory in Poplarville, MS. The primary purpose of the field day is to showcase new and upcoming cultivar releases and promising selections. Short in-field presentations are given by MSU Extension personnel and USDA-ARS scientists. Both the workshop and field day are considered joint efforts of MSU and USDA-ARS.

The Beaumont Horticulture Field Days (BH-FD) are held annually, with an average attendance of 75 participants (Figure 1). The Mississippi Agricultural and Forestry Experiment Station (MAFES) Beaumont Horticulture Unit (BHU) conducts the Beaumont Horticulture Field Day at the Beaumont Horticultural Unit in Beaumont, Mississippi during the first Thursday in June. The BH-FD is joined by vegetable and fruit growers, extension personnel, students, state and nongovernmental agencies, and other university researchers from the Gulf Coast regions of Mississippi, Alabama, and Louisiana. The attendees listen to the latest updates from researchers and extension specialists at Mississippi State University and state and industry experts.

The CREC annual Producer Advisory Council Meeting (CREC-PAC) was attended by more than 100 horticultural producers and practitioners per year (Figure 1). This yearly meeting started in 2008 . Individuals invited to this Advisory Council are selected as representatives of specific commodities. They are asked by Mississippi State University to evaluate and provide future research and educational programs for their commodity. The breakout sessions include agronomic crops, apiculture, commercial ornamental and horticulture, forestry, fruits and vegetables, poultry, horse and small ruminants, livestock, and marine resources.

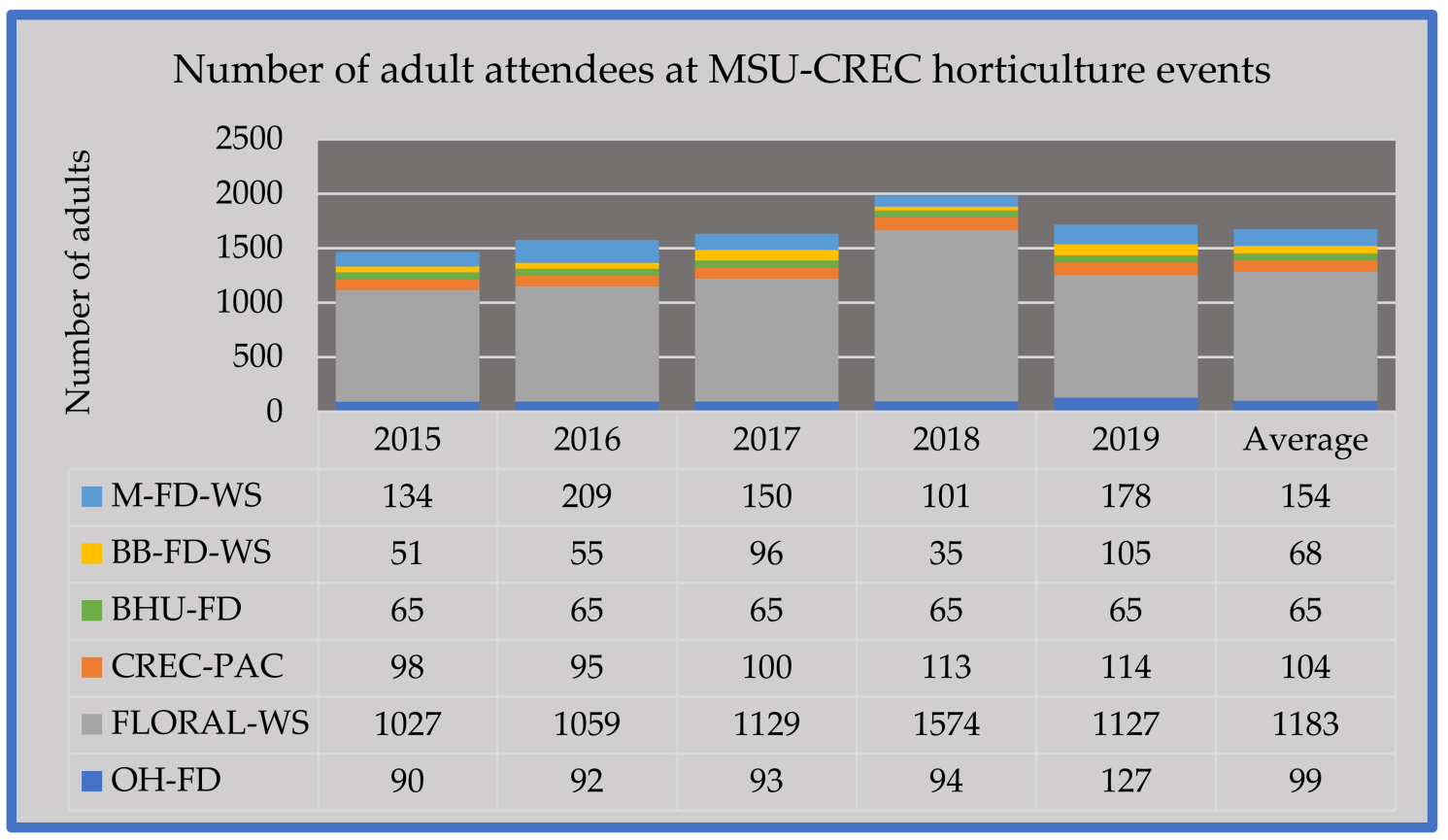

Figure 1. Shows the number of adult attendees at the horticulture events conducted at the MSU-CREC research and extension facilities during the last five years.

MSU-CREC's floral programs provide research-based and best-practice information for consumers, retailers, wholesalers, and growers. These programs result in informed buyers who stimulate a greater demand for floricultural and related products.

The Floral Enthusiast program aids and encourages consumers to purchase, grow, and arrange fresh flowers and ornamental interior plants. To date, 217 people have completed hands-on workshops and feel enabled to design independently, thus increasing the potential for buying more cut flowers to decorate their homes and businesses. In a special program, eighty Biloxi Public School fourth-grade students were introduced in order to cut flowers grown by Mississippi producers Happy Trails Flower 
Farm, Dennis; Little Blue Stem Farm, Carthage; and Coastal Ridge Farm, Picayune. Students learned how to identify the cut flowers and made arrangements with readily available flowers.

Master Floral Designer (MDF): Since January 2017, 36 people have completed the 14-week training sessions and have earned a certification as MSU Extension Master Floral Designers. Candidates earn certificates through volunteer activities promoting the beauty and appreciation of floral design. Volunteers have located wholesale-to-the-public sources for bulk cut flowers and use them for many types of events. They have also formed an informal cooperative for buying floral supplies amongst themselves such as floral foam and other hard good specialty products. MFDs were key planners and organizers for a Kids Camp in Floral Design, introducing 17 Gulf Coast 8-12-year-olds to the art of floral design and interior plants. Projects stressed the names of plants and the enjoyment that flowers can bring to places where people work and live.

Professional Florist Program (PFP): By adopting best practices, marketing and advertising promotions, and sales and design efficiency were increased. A three-day Wedding Floral Design Workshop was taught at the North Mississippi Research and Extension Center in Verona to eight professional florists, four of whom are farmer-florists who not only design and retail flowers but produce them on their farms. As an output from the training, one farmer has designed and implemented an advertising card that she hands out at farmer markets. Another farmer florist has reported that she has completed several wedding orders since the workshop and finds that she creates with more confidence and efficiency. A third farmer florist has responded that her floral design efficiency has increased due to the implementation of the recommended floral design products and methods.

Four Seasons of Floral Design (FSFD): Through a block grant from the Mississippi Department of Agriculture and Commerce, 100 County Agents and MSU Extension Volunteers have been trained in floral design basics using Mississippi-grown cut flowers and foliage. Four training sessions were held in April through May. Participants were asked to deliver educational programs to at least ten people during the next year, using the learned information and skills. Early results have found that multiple programs have already been taught in all four regions. These programs are designed to raise consumer appreciation and the use of Mississippi-grown cut flowers and ornamental foliage in floral design.

The annual Ornamental Horticulture Field Day (OHFD) is held at the South Mississippi Branch Experiment Station (SMBES) in Poplarville, Mississippi, during the first Thursday in October. The OHFD has been going on since it started in 1973. The field day is attended by nursery and landscape professionals, master gardeners, extension personnel, students, home gardeners, and other university researchers from the Gulf Coast regions of Mississippi, Alabama, and Louisiana. The participants learn about the latest research updates from researchers at Mississippi State University and the UDSA-ARS Southern Horticultural Laboratory and provide valuable feedback to these research professionals. The Ornamental Horticulture Field Days (OH-FD) averaged about 100 attendees per year (Figure 1).

\title{
2.2. Survey of Participants Opinions
}

The attendees of the Ornamenal Horticulture Field Days in 2017 and 2019 were asked to participate in a survey of their opinions about the horticulture research and extension activities at MSU-CREC. The five questions soliciting their opinions on the economic impacts of horticulture research and extension are listed below.

Did you learn useful information from the extension events or activities, field days, producer meetings, publications, presentations, radio, television, media, online, and social media networking conducted by the Horticulture Research Program during the last five years? (Please check only one):

\author{
Strongly disagree \\ Disagree \\ Neutral \\ Agree \\ Strongly agree
}


The new information you learned from the Horticulture Research Program was applied to your household, office, or business operations during the last five years? (Please check all that apply):

Own household

Private business

Local government office

State or federal regulatory agency

Nonprofit organization

Research or extension project

Other (please specify)

The new information you learned from the Horticulture Research Program benefitted your household or business operations during the last five years? (Please check one):

Strongly disagree

Disagree

Neutral

Agree

Strongly agree

Please specify the information your household, office, or business needs most on horticulture, vegetables, fruits, and nuts. What are the preferred means of access to the Horticulture Research Program for your household, business, or office? (Please check all that apply):

Online newsletter

Emails

Social media networks

Websites

Presentations in workshops, field days, meetings, conferences

Extension publications, research bulletins

Journal articles

Other (please specify)

\section{Results}

\subsection{Number of Participants}

The number of participants consisted of adults who attended horticulture events at the MSU-CREC research and extension facilities. During the past five years (2015-2019), the annual number of adult attendees at horticulture events averaged over 1600 persons or a total of more than 8400 producers, master gardeners, and research and extension personnel (Figure 1).

The Muscadine Field Days and Workshops (M-FD-WS) averaged more than 150 attendees per year. About 70 attendees participated in the Blueberry Field Days and Workshops (BB-FD-WS) per year. The Beaumont Horticulture Field Days (BH-FD) are held annually, with an average attendance of 65 participants (Figure 1).

The MSU-CREC annual Producer Advisory Council meeting (CREC-PAC) was attended by more than 100 horticultural producers and practitioners. Floral Workshops (FLORAL-WS) topped the list with almost 1200 adults per year. The Ornamental Horticulture Field Days (OH-FD) averaged about 100 attendees per year (Figure 1). 


\subsection{The Usefulness of Horticulture Information}

Samples of the OH-FD, BB-FD-WS, and BHU-FD participants completed the voluntary surveys conducted at the end of these horticulture events. A total of 134 participants of the OH-FD, 470 producers who attended the BB-FD-WS, and 22 attendees of BHU-FD responded to this question.

Most of the BB-EW, M-FD, and OH-FD participants learned useful information from horticulture events during the last five years (Figure 2). Ninety-three percent of the participants learned helpful information from horticulture events over the previous five years. About 64 percent strongly agreed, 29 percent agreed, four percent were neutral, and three percent strongly disagreed or disagreed with the statement.

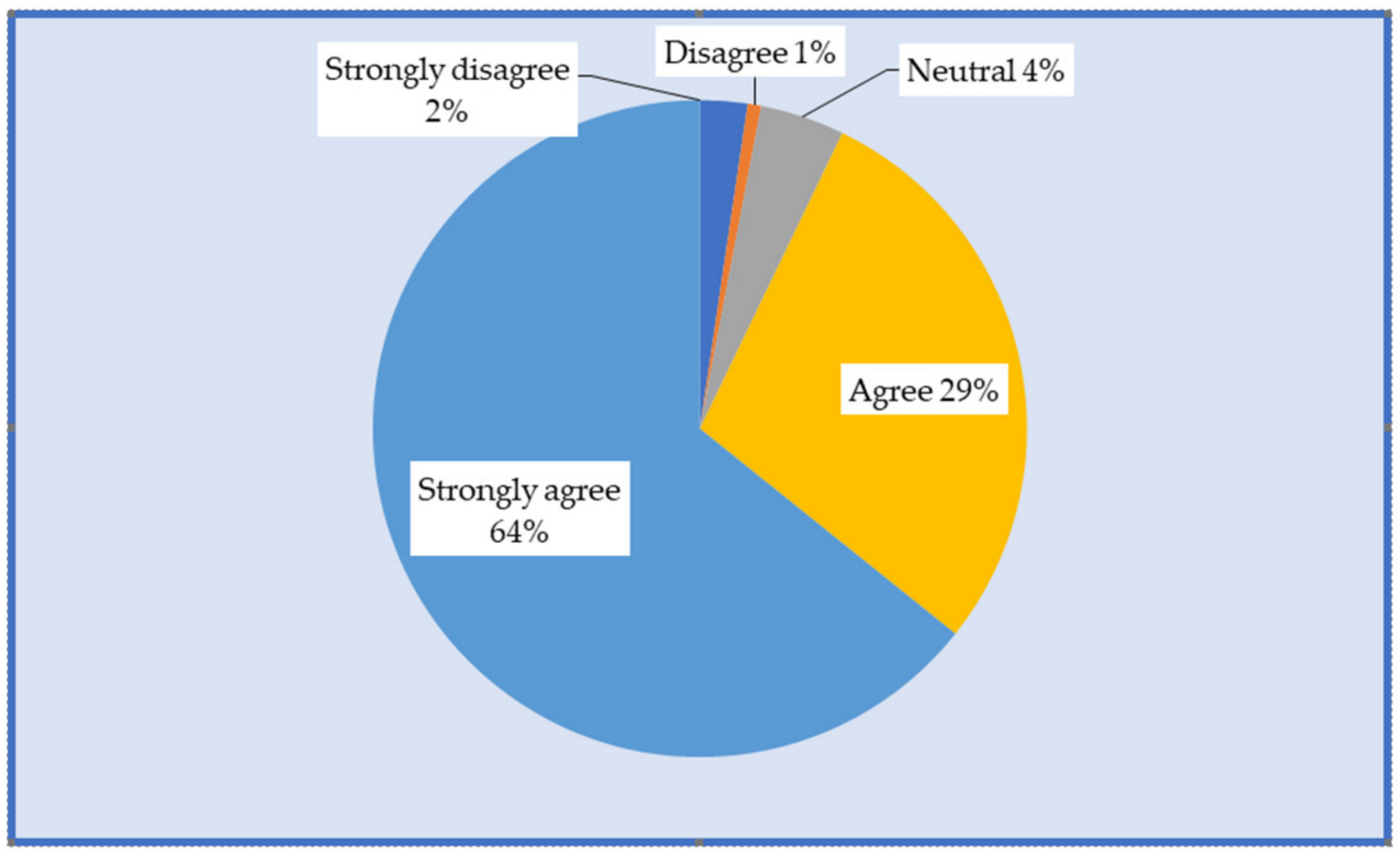

Figure 2. Shows the percent distribution of respondents on the question below. Did you learn useful information from the extension events or activities, field days, producer meetings, publications, presentations, radio, television, media, online, and social media networking conducted by the Horticulture Research Program during the last five years?

\subsection{Application of Horticulture Information Learned}

Ninety-three percent of the participants who attended the OH-FD applied the new information learned from the Horticulture Research Program during the last five years to their households (Figure 3). Nineteen percent of the participants used the new information gained for their research and extension projects. Sixteen percent of the participants applied the new knowledge learned to their nonprofit organizations. Seven percent of the participants used the new information acquired in their private businesses. 


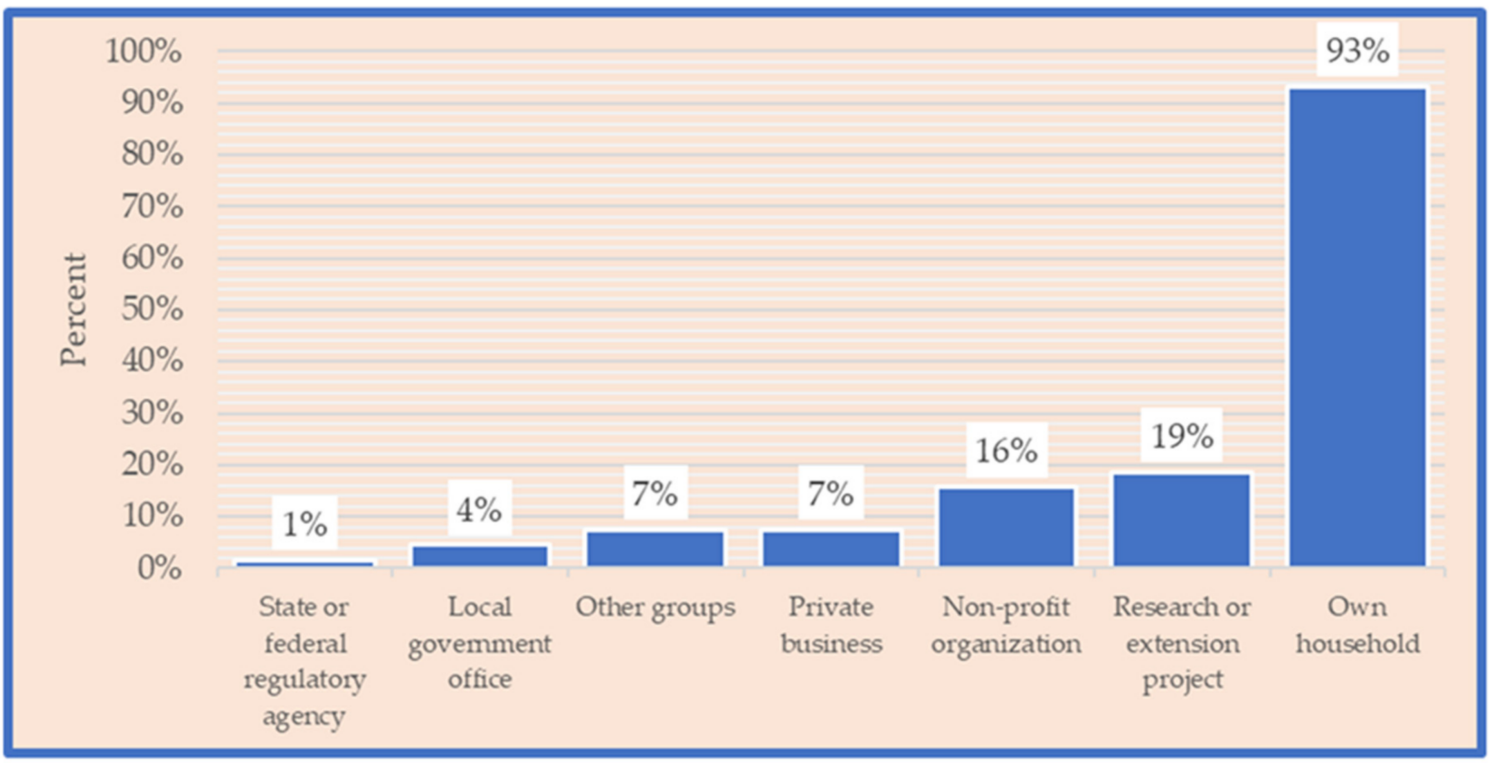

Figure 3. Shows the percent distribution of respondents on the question below. The new information you learned from the Horticulture Research Program was applied to your household, office, or business operations during the last five years.

\subsection{Benefits of New Horticulture Information Learned}

Most of the OH-FD participants benefitted from new information learned during the last five years. Seventy-four percent of participants who attended the OH-FD gained from new knowledge they learned from the Horticulture Research Program during the last five years (Figure 4). About fourteen percent were neutral, and 13 percent strongly disagreed with the statement.

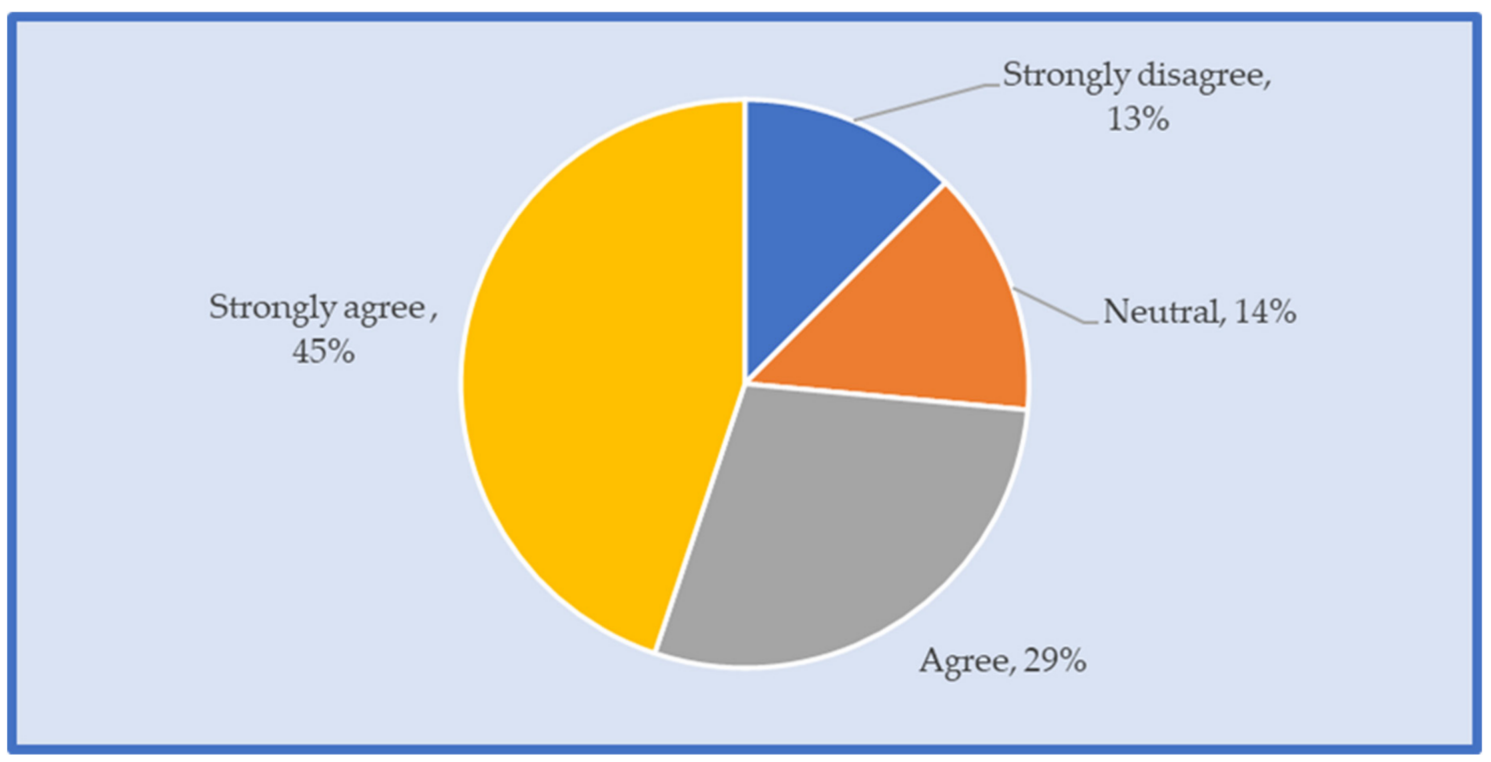

Figure 4. Shows the percent distribution of respondents on the question below. The new information you learned from the Horticulture Research Program benefitted your household or business operations during the last five years.

\subsection{Additional Horticulture Information Needed}

The participants of the horticulture events identified general horticulture information that they needed in their respective households and businesses. Thirty percent of the OH-FD participants needed more information on pests, insects, and weeds. Nineteen percent required more information 
on vegetables. Sixteen percent wanted more information on diseases. Twelve percent asked for more information on new plants. Eight percent requested more information on fruits and nuts (Figure 5).

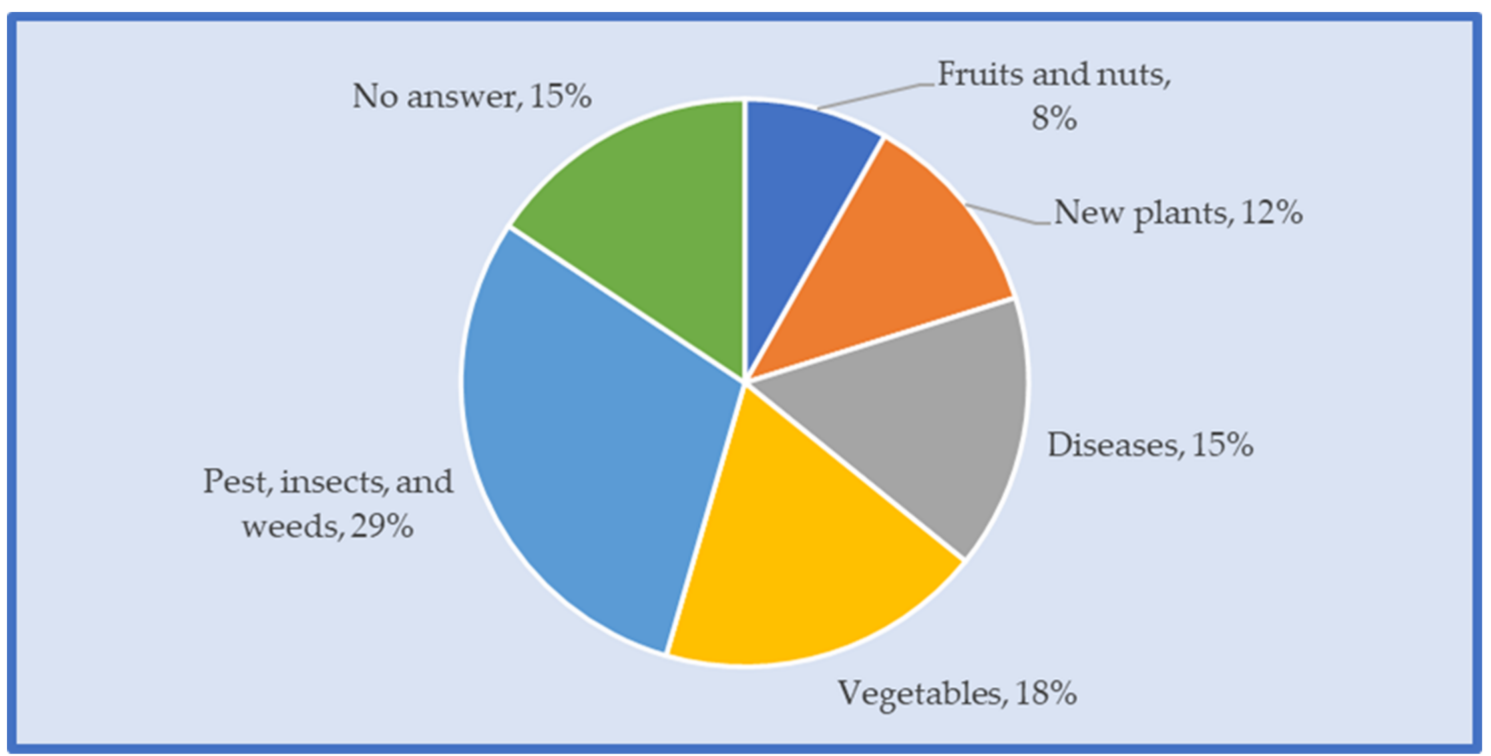

Figure 5. Shows the percent distribution of respondents on the question below. Please specify the information your household, office, or business needs most on horticulture, vegetables, fruits, and nuts.

There is an anecdotal explanation for the 15 percent who did not answer the question related to the preferred source of information. Many people in the floral programs want to learn anything they can about floral design and are happy to be there. People value the opportunity to learn, but during field days they value the electric feeling of being around horticulture knowledge and recommendations they trust. There is a brand loyalty to Mississippi State University.

During the recent CREC-PAC meetings, the various needs for additional information by participants were summarized in the proceedings [8-12]. The information needs were grouped by commodities, and those involving horticulture, flowers, vegetables, fruits, and nuts are listed below:

Pests and diseases on the horizon

Fruit and vegetable disease publications

Roses with cane diseases

Rose rosette-mite species distribution and presence in Mississippi

Disease problems and laboratory diagnostics

Vase life of potential foliage crops for floral design

Best native ornamentals

Fruit and nut/vegetable enterprise planning templates

Instruction on setting up an email distribution system for mass marketing

Developing young professionals for the nursery industry

Immigration issues and labor availability

List of contact information compiled for muscadines and grapes

\subsection{Preferred Sources of Horticulture Information}

Sixty-six percent of the OH-FD participants preferred presentations as the means of access to the Horticulture Research Program. Newsletters were preferred by 54 percent of the participants. Publications were chosen by 53 percent of the participants. Forty-four percent of the participants preferred emails. Thirty-six percent selected websites. Twenty-five percent desired social media. Eleven percent favored articles (Figure 6). 


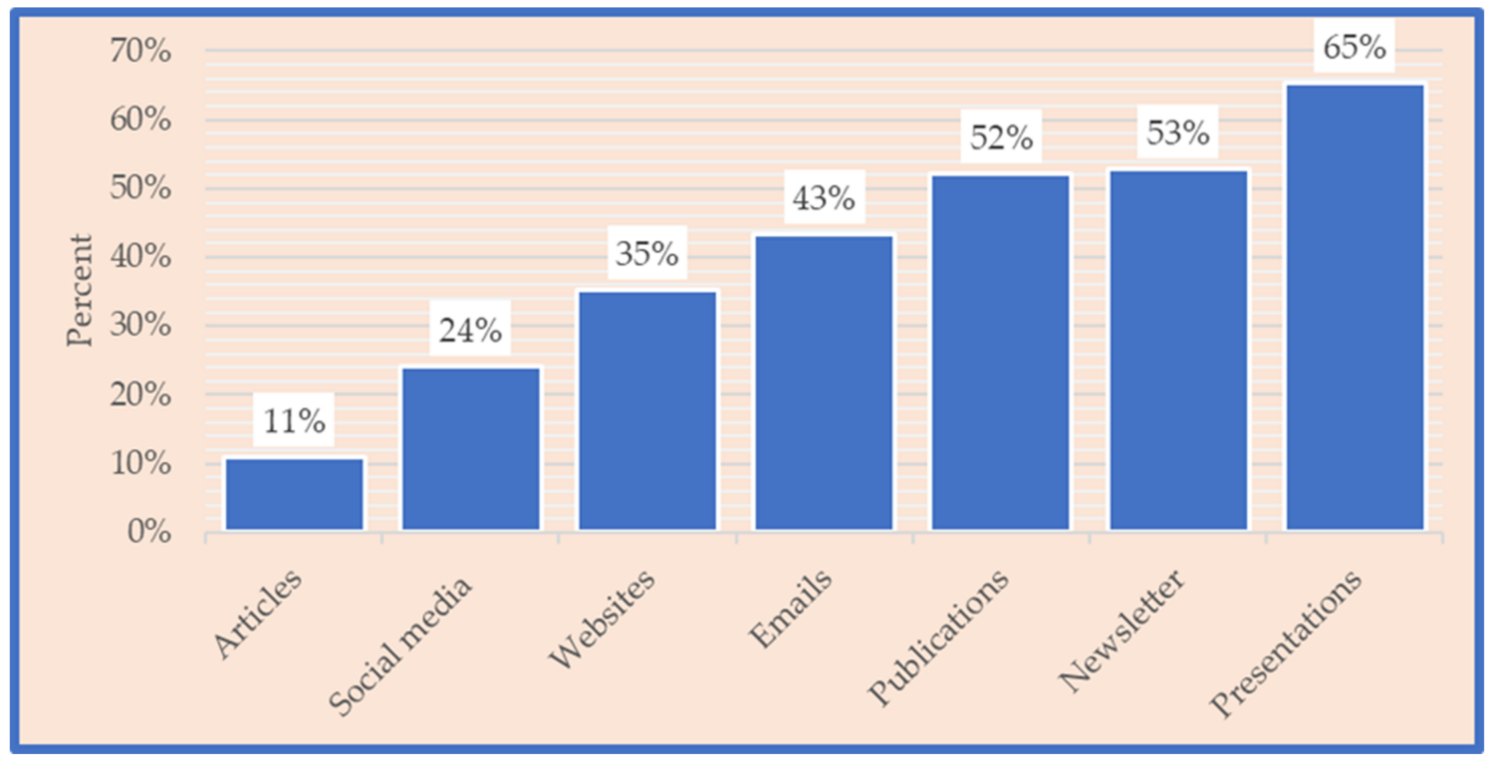

Figure 6. Shows the percent distribution of respondents on the question below. What are the most preferred means of access to the Horticulture Research Program for your household, business, or office?

\section{Discussion}

Horticulture research and extension are essentially public goods funded for the benefit of the public. Economic impact assessments are necessary to justify the continued funding of these research and extension programs. The majority of the participants viewed horticulture research and extension at MSU-CREC as providing useful information that benefitted their households, businesses, or nonprofit organizations.

The preferred means of access to horticulture information are presentations, newsletters, and publications. From an educational standpoint, live presentations such as field days often allow learners to be in an environment where the research occurs. Onsite programs enrich participants' experience by spurring additional questions and ideas.

The participants asked for more information on pests, insects, weeds, vegetables, new plants and diseases, fruits, and nuts. This paper is limited to the qualitative assessment of the participants of horticulture events. The quantitative assessment is presented in a follow-up manuscript, which is now in preparation. This qualitative assessment is limited to horticulture information's usefulness and benefits to participating individual households, businesses, or organizations.

The specific objectives of qualitative and quantitative assessments of research and extension activities have to be specific, measurable, attainable, realistic, and time-bound. Survey instruments have to be comparable for the compilation and analysis. We suggest that regular voluntary assessment surveys be conducted in future horticulture events using similar survey instruments. Another suggestion is to put together a few focus groups as another data-gathering system.

Author Contributions: Conceptualization, B.P., P.K., C.C., E.B., E.S., J.D., G.B. and S.L.; methodology, B.P.; software, B.P.; validation, B.P.; formal analysis, B.P.; investigation, B.P., P.K., C.C., E.B., E.S., J.D., G.B. and S.L.; resources, B.P., P.K., C.C., E.B., E.S., J.D., G.B. and S.L.; data curation, B.P.; J.D., E.S., C.C., E.B.; writing-original draft preparation, B.P.; writing-B.P., P.K., C.C., E.B., E.S., J.D., G.B. and S.L.; review and editing, B.P., P.K., C.C., E.B., E.S., J.D., G.B. and S.L.; visualization, B.P.; supervision, B.P.; project administration, B.P.; funding acquisition, P.K., C.C., E.B., E.S., J.D., G.B., B.P. All authors have read and agreed to the published version of the manuscript.

Funding: This research received no external funding.

Acknowledgments: This publication is a contribution of the Mississippi Agricultural and Forestry Experiment Station. This material is based upon work supported in part by the National Institute of Food and Agriculture, U.S. Department of Agriculture, Hatch project under accession number 1014723.

Conflicts of Interest: The authors declare no conflict of interest. 


\section{References}

1. Alston, J.M.; Pardey, P.G.; Carter, H.O. Valuing UC Agricultural Research and Extension, Agricultural Issues Center Pub. No. 1; University of California: Davis, CA, USA, 1994.

2. Birkhaeuser, D.; Evenson, R.E.; Feder, G. The economic impact of agricultural extension: a review. Econ. Dev. Cult. Chang. 1991, 39, 607-650. [CrossRef]

3. Evenson, R.E. Economic impacts of agricultural research and extension. In Handbook of Agricultural Economics; Gardner, B., Rausser, G.C., Eds.; Elsevier: Amsterdam, The Netherlands, 2001; Volume 1, pp. 573-628.

4. Wang, S.L. Cooperative extension system: Trends and economic impacts on U.S. agriculture. Choices. Agric. Appl. Econ. Assoc. 2014. Available online: http://www.choicesmagazine.org/magazine/pdf/cmsarticle_355.pdf (accessed on 18 June 2018).

5. Hall, C.R. Making Cents of Green Industry Economics. HortTechnology 2010, 20, 832-835. [CrossRef]

6. Hodges, A.W.; Hall, C.R.; Palma, M.A.; Khachatryan, H. Economic contributions of the green industry in the United States in 2013. HortTechnology 2015, 25, 805-814. [CrossRef]

7. NASS. Quick Stats. U.S. Department of Agriculture, National Agricultural Statistics Service. 2020. Available online: https://quickstats.nass.usda.gov/ (accessed on 1 October 2020).

8. CREC-PAC. Producer Advisory Council Commodity Session Notes; Mississippi State University, Coastal Research and Extension Center: Biloxi, MS, USA, 2020; Available online: http://coastal.msstate.edu/advisory (accessed on 2 October 2020).

9. CREC-PAC. Producer Advisory Council Commodity Session Notes; Mississippi State University, Coastal Research and Extension Center: Biloxi, MS, USA, 2019; Available online: http://coastal.msstate.edu/advisory (accessed on 2 October 2020).

10. CREC-PAC. Producer Advisory Council Commodity Session Notes; Mississippi State University, Coastal Research and Extension Center: Biloxi, MS, USA, 2018; Available online: http://coastal.msstate.edu/advisory (accessed on 2 October 2020).

11. CREC-PAC. Producer Advisory Council Commodity Session Notes; Mississippi State University, Coastal Research and Extension Center: Biloxi, MS, USA, 2017; Available online: http://coastal.msstate.edu/advisory (accessed on 2 October 2020).

12. CREC-PAC. Producer Advisory Council Commodity Session Notes; Mississippi State University, Coastal Research and Extension Center: Biloxi, MS, USA, 2016; Available online: http://coastal.msstate.edu/advisory (accessed on 2 October 2020).

Publisher's Note: MDPI stays neutral with regard to jurisdictional claims in published maps and institutional affiliations.

(C) 2020 by the authors. Licensee MDPI, Basel, Switzerland. This article is an open access article distributed under the terms and conditions of the Creative Commons Attribution (CC BY) license (http://creativecommons.org/licenses/by/4.0/). 